\title{
GERAKAN PENGHIJAUAN SEBAGAI RINTISAN DESA WISATA UNTUK MENINGKATKAN INCOME MASYARAKAT DI DESA SUMOKALI, CANDI, SIDOARJO
}

Nurul Imamah, Fakultas Ekonomi dan Bisnis, Universitas Bhayangkara Surabaya, nurulimamah11@yahoo.com

\begin{abstract}
:
The reforestation movement through planting 100 red shoots is the first step towards a tourist village that will have a positive impact on the village community. If this program is implemented properly and can be followed by the local community, the tourism village program will be achieved. Education of the reforestation movement in order to increase the income of the Sumokali village community towards a tourist village with the target of MSMEs, PKK groups and Youth Organizations. The team planned several programs related to this theme and implemented them by complying with strict health protocols because currently the Covid-19 pandemic is still in progress. This community service program is expected to achieve the objectives of the theme, which is to help increase community income through existing Micro, Small and Medium Enterprises (MSMEs) by providing socialization, training and implementation of the program. The program implementation method is carried out in several stages, including: 1) the preparation stage; 2) implementation stage; 3) evaluation stage. The results of the implementation of this community service program is implementing the planting of 100 red shoots. Furthermore, the success of the tourism village program can increse income dan help improve the quality of the environment in Sumokali village so as to create a healthy community as a supporter of the tourism village program and increase community income through MSMEs.
\end{abstract}

Keywords: : Greening, Income, Tourism Village

\begin{abstract}
Abstrak:
Gerakan penghijauan melalui penanaman 100 pucuk merah merupakan langkah awal menuju desa wisata yang akan berdampak positif bagi masyarakat desa. Jika program ini dilaksanakan dengan baik dan dapat diikuti oleh masyarakat sekitar, maka program desa wisata akan tercapai. Edukasi gerakan penghijauan dalam rangka meningkatkan pendapatan masyarakat desa Sumokali menuju desa wisata dengan sasaran UMKM, kelompok PKK dan Karang Taruna. Tim merencanakan beberapa program terkait tema ini dan melaksanakannya dengan mematuhi protokol kesehatan yang ketat karena saat ini pandemi Covid-19 masih berlangsung. Program pengabdian masyarakat ini diharapkan dapat mencapai tujuan dari tema yaitu membantu peningkatan pendapatan masyarakat melalui Usaha Mikro Kecil Menengah (UMKM) yang ada dengan memberikan sosialisasi, pelatihan dan implementasi program. Metode pelaksanaan program dilakukan dalam beberapa tahapan, antara lain: 1) tahap persiapan; 2) tahap implementasi; 3) tahap evaluasi. Hasil dari pelaksanaan program pengabdian masyarakat ini adalah pelaksanaan penanaman 100 pucuk merah. Selanjutnya keberhasilan program desa wisata dapat meningkatkan pendapatan dan membantu meningkatkan kualitas lingkungan di desa Sumokali sehingga tercipta masyarakat yang sehat sebagai pendukung program desa wisata dan peningkatan pendapatan masyarakat melalui UMKM.
\end{abstract}

Keywords: Penghijauan, Pendapatan, Desa Wisata

Copyright ( 2021 , Dinamis: Jurnal Pengabdian Kepada Masyarakat https://ejournal.feunhasy.ac.id/index.php/dinamis 


\section{PENDAHULUAN}

Desa Wisata merupakan suatu desa yang memiliki ciri khas tersendiri yang mencerminkan keaslian desanya, baik dari aspek kehidupan sosial budaya, adat istiadat sehari-hari, arsitek bangunan dan struktur tata ruang desa, dan berpotensi untuk dikembangkan sebagai destinasi pariwisata, misalnya atraksi, kuliner, suvenir, dan kebutuhan pariwisata lainnya, (Arismayanti et al., 2015). Pengembangan suatu wilayah menjadi desa wisata harus direncanakan dengan matang dan hati-hati agar dapat dikontrol dengan baik oleh penduduk lokal. Isu utama dalam pengembangan desa wisata adalah mengenai kontribusi positif aktifitas pariwisata di desa wisata terhadap kehidupan ekonomi masyarakat lokal (Hariyanto, 2016). Dengan adanya desa wisata akan tercipta interaksi antara kebutuhan wisatawan dan pemenuhan kebutuhan tersebut oleh penduduk, sehingga terjadi efek di mana akan terjadi transaksi ekonomi baik jasa maupun barang. Desa wisata dalam artian bukan desa yang memiliki fasilitas wisata saja, namun bisa juga diartikan desa tersebut diminati atas kualitas udara di desa tersebut ataupun bisa pemandangan jalan yang indah sehingga menimbulkan estetika dan kesan terhadap yang yang melihatnya.

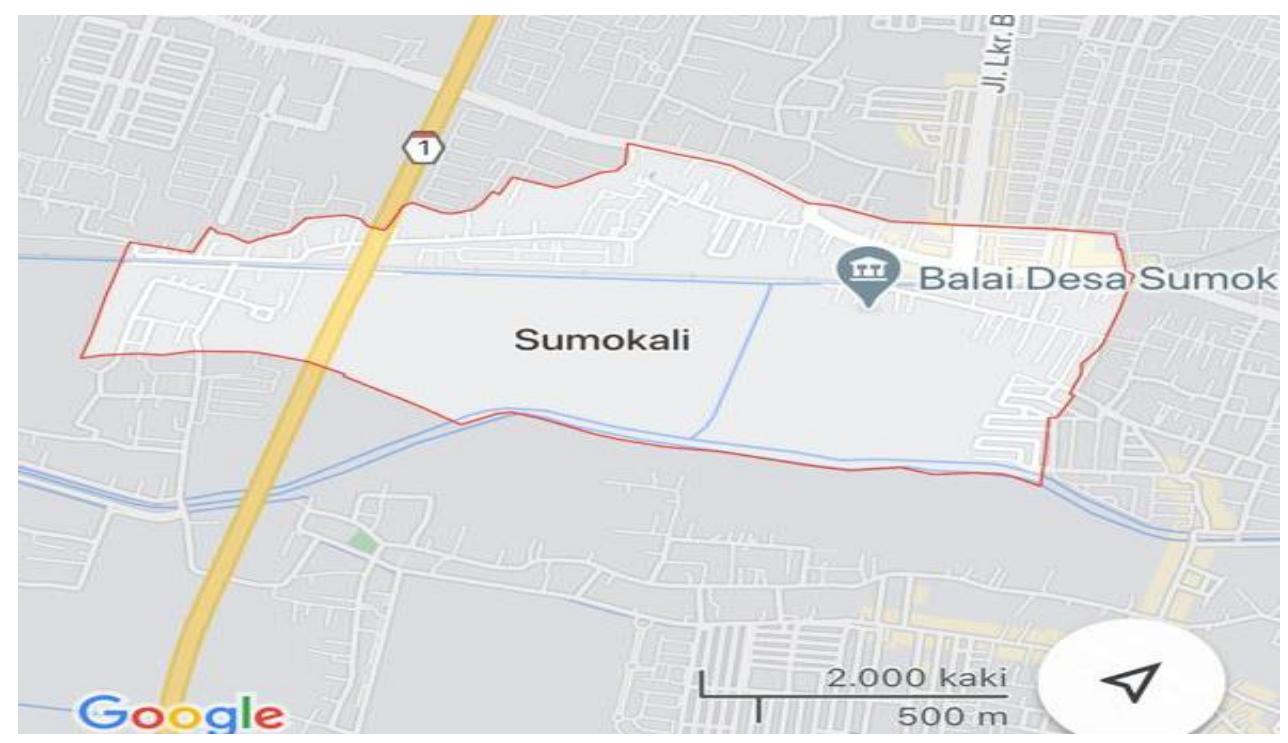

Gambar 1. Peta Desa Sumokali, Kecamatan Candi, Kabupaten Sidoarjo

Desa Sumokali terletak di bagian utara Kecamatan Candi, Kabupaten Sidoarjo. Desa Sumokali berjarak $\pm 3,5 \mathrm{~km}$ dari pusat pemerintahan Kabupaten Sidoarjo, dan berjarak $\pm 35 \mathrm{~km}$ dari ibukota Provinsi Jawa Timur. Desa Sumokali dibagi dalam dua dusun yaitu Sumokali dan Nyamplung. Dusun Sumokali terletak di sebelah timur, sedangkan dusun Nyamplung terletak di sebelah barat wilayah Sumokali. Kondisi umum dusun Sumokali adalah pemukiman penduduk dengan sejumlah besar pemukiman padat penduduk, bahkan berdiri perumahan yaitu Perumahan Sidokare Asri untuk RW III, dan yang sebagian besar perumahan berdiri di wilayah Kelurahan Sidokare. Di wilayah 
Sumokali juga berdiri Perumahan Istana Megah Asri untuk RW I, dan yang sebagian perumahan berdiri di wilayah Desa Teggulunan. Selain itu berdiri beberapa pertokoan di Dusun Sumokali karena letaknya yang strategis dan mudah dijangkau oleh warga Sumokali dan sekitarnya. Sementara Dusun Nyamplung berupa pemukiman padat penduduk dan lahan pertanian. Jumlah pertokoan yang berdiri di Dusun Nyamplung lebih sedikit daripada di Dusun Sumokali.

Untuk mencapai kelestarian lingkungan, manusia mulai menyadari perlunya penghijauan untuk mencegah terjadinya masalah lingkungan di masa depan sehingga dibutuhkan upaya nyata yang harus dilakukan untuk meningkatkan kualitas lingkungan. Salah satunya adalah dengan menumbuhkan sikap peduli lingkungan melalui pendidikan lingkungan kepada anak-anak sejak usia dini (Adriansyah, et al., 2019). Kemudian tim Pengabdian Kepada Masyarakat dari Universitas Bhayangkara (UBHARA) Surabaya kelompok 078 mengusulkan dibuatnya Desa Wisata. Sebagai langkah awal pembuatan Desa Wisata perlu dilakukan penghijauan dengan menanam 100 pohon pucuk merah di beberapa lokasi desa tersebut, dengan harapan keindahan yang akan tampak dalam jangka panjang, dan dapat membantu menambah kualitas udara di lingkungan desa Sumokali.

\section{METODE KEGIATAN}

Pelaksanaan kegiatan ini dilakukan melalui empat tahap, antara lain: 1) tahap persiapan, pada tahap ini dilakukan identifikasi potensi desa guna untuk menganalisis permasalahan yang ada; 2) tahap pelaksanaan, tahap ini dilakukan observasi lapangan untuk mengetahui kondisi yang ada; 3) tahap implementasi, (dilakukan sosialisasi program dan melakukan penanaman 100 pohon pucuk merah, pelatihan, pemasaran online, penyusunan laporan keuangan serta pemanfaatan potensi lokal, juga berbagi masker dalam rangka meningkatkan protokol kesehatan); 4) tahap evaluasi program, tahap terakhir ini bertujuan melakukan evaluasi hasil program pengabdian kepada masyarakat. Kegiatan Pengabdian Kepada Masyarakat dari Universitas Bhayangkara (UBHARA) Surabaya kelompok 078 dilaksanakan tanggal 29 Mei 2021 sampai dengan tanggal 14 Juni 2021.

\section{HASIL DAN PEMBAHASAN}

Program kerja dibuat dan dilaksanakan untuk memecahkan berbagai masalah yang dihadapi oleh masyarakat. Program kerja tersebut dilaksanakan serentak dan berjalan secara bersamaan di beberapa lokasi di wilayah Administrasi Desa Sumokali. Kegiatan dikemas dan di laksanakan dengan berbagai tujuan berdasarkan Tema yang telah ditentukan. Adapun pembahasan secara rinci dari kegiatan pengabdian kepada masyarakat di desa Sumokali, Candi, Sidoarjo adalah sebagai berikut: 


\section{Tahap Persiapan}

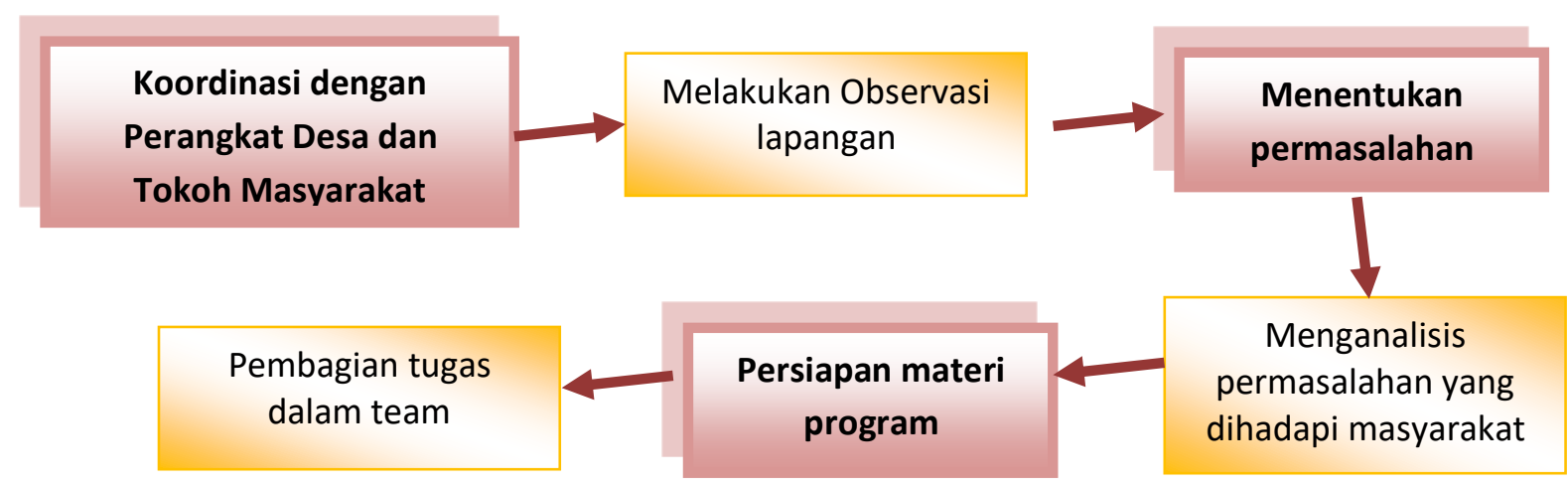

Gambar 2. Skema Tahap Persiapan

\section{Tahap Pelaksanaan}

\section{a. Perencanaan Kegiatan}

Perencanaan program pengabdian kepada masyarakat dimulai dengan melakukan koordinasi dengan perangkat desan serta masyarakat desa, kemudian dilanjut dengan observasi langsung untuk menentukan masalah yang sedang dialami di desa sumokali. Observasi dimulai dari meninjau langsung tempat yang akan ditanami tanaman pucuk merah dan melakukan dialog antara Bapak Kepala Desa Sumokali terkait perizinan dan potensi Desa Sumokali dan salah satu bentuk nyata pendekatan dengan penduduk adalah sosialisasi dengan penduduk setempat.

Program kerja ini dibuat dan dilaksanakan untuk memberikan dorongan terciptanya desa wisata melalui penanaman pohon guna terciptanya lingkungan yang indah sehingga menimbulkan daya tarik di kemudian hari sehingga berdampak pada ekonomi masyarakat Desa Sumokali. Harapan selanjutnya semakin banyak masyarakat yang berjualan sehingga mampu meningkatkan pendapatan mereka. Desa Wisata bisa juga meningkatkan harga jual aset dikarenakan menjadi lokasi wisata dan strategis. Agar tercapai desa wisata melalui penghijauan maka dilakukan penanaman 100 pohon di Desa Sumokali, Kegiatan ini cukup mendapatkan respon positif dari Kepala desa Sumokali beserta perangkat desa, respon positif juga didapat dari masyarakat setempat

Pelaksanaan program sesuai jadwal kegiatan yang telah direncanakan selama satu bulan setiap Sabtu dan Minggu. Setiap program yang sudah selesai dilaksanakan akan monitor dan dievaluasi, Hal tersebut dilakukan agar setiap anggota kelompok mengetahui kekurangan dan kelebihan dalam menjalankan program tersebut, dan diharapkan dengan adanya monitoring dan evaluasi akan menambah keberhasilan Program Kerja kedepannya serta meminimalisir kekurangan yang terjadi 
Volume 1 Nomor 1, Juni 2021

\section{b. Kelompok Sasaran}

Sasaran dari program Pengabdian Kepada Masyarakat ini adalah masyarakat umum ibu-ibu PKK dan UMKM, dengan adanya kegiatan ini diharapkan masyarakat daerah Sumokali akan sadar tentang edukasi penghijauan dan menjadikan desanya sebagai desa wisata sehingga bisa meningkatkan income bagi masyarakat desa tersebut.

\section{c. Sosialisasi Program}
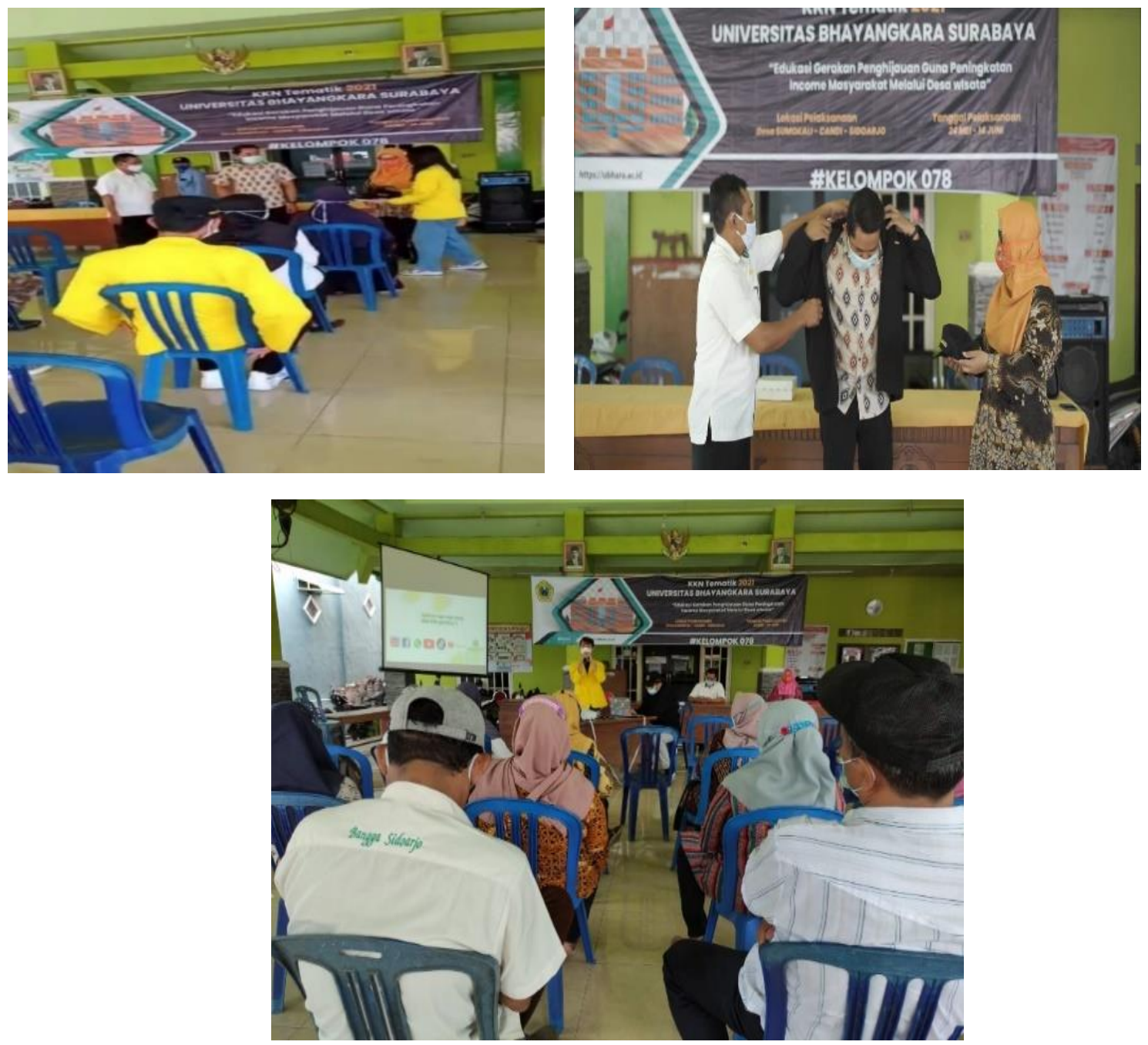

Gambar 3. Sosialisasi Progam ke Masyarakat

Program pengabdian kepada masyarakat berupa kuliah kerja nyata tematik di desa sumokali dilaksanakan program dengan lancar. Acara ini dihadiri oleh 30 peserta, baik dari perangkat desa maupun masyarakat dengan mematuhi protokol kesehatan dengan menjaga jarak tempat duduk peserta, pemberian handsanitizer serta masker, sehingga dapat dipastikan kegiatan tersebut telah mematuhi prokes secara ketat. 
Program sosialisasi sebagai salah satu program dari tema dilaksanakan ini. Untuk menambah pengetahuan/wawasan masyarakat Desa Sumokali. Karena pengetahuan sangat penting dengan adanya pengetahuan bisa menjadi modal untuk perencanaan atau pandangan ke depannya untuk yang positif. Program tersebut cukup berhasil, terbukti dengan banyaknya masyarakat yang datang ke acara sosialisasi dari program pengabdian masyarakat.

Sosialisasi bertujuan untuk meningkatkan edukasi pentingnya penghijauan guna memberikan perhatian warga sekitarnya sehingga dapat meningkatkan pendapatannya melalui desa wisata, dimana desa sumokali memiliki ikon tersendiri bagi warganya dan masyarakat luar desa tersebut.

\section{d. Penerapan Program}

Kegiatan utama dalam program pengabdian kepada masyarakat ini berupa penanaman 100 pohon pucuk merah dengan mematuhi arahan kepala desa sumokali yakni bapak Subiyanto. Sebelum pelaksanaan penanaman 100 pohon pucuk merah, dilakukan penyerahan dahulu kepada kepala desa Sumikali, dimana acara penyerahan pohon pucuk merah secara simbolik yang diwakili Ibu Dr. Nurul Imamah.,SE, ME dan anggota PKM kelompok 078.
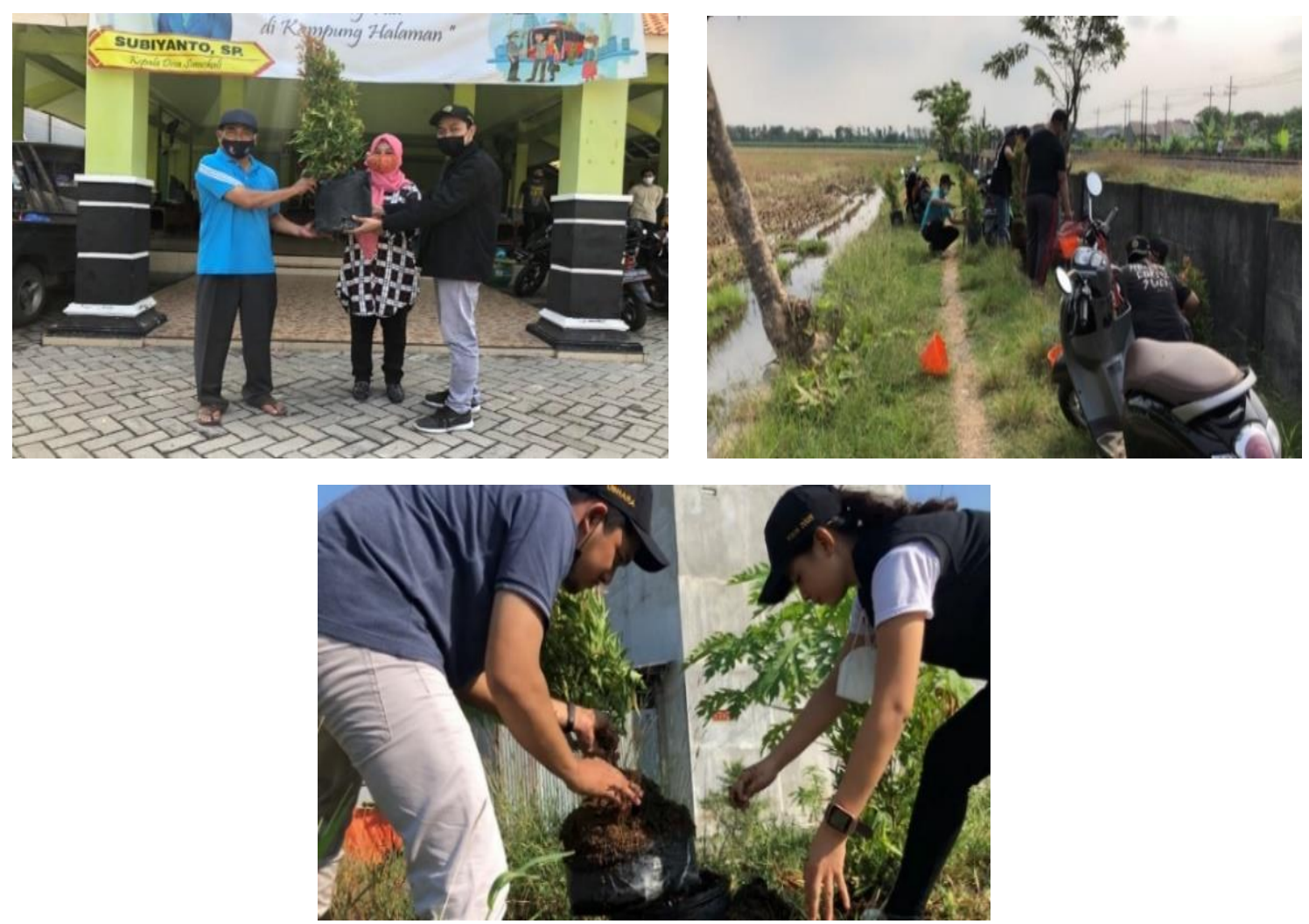

Gambar 4. Pelaksanaan Progam

Lokasi kegiatan penanaman pohon pucuk merah berada di 4 lokasi. Lokasinya dekat tepi bantaran sungai, tepi sawah (yang akan dibangun jalan raya baru), TPQ 
Rodotun Ni'mah dan Balai Desa Sumokali. Program penanaman pohon pucuk merah yang menjadi sasaran utama pada program ini yaitu dua lokasi yang ditargetkan menjadi titik utama dari program ini, yakni di jalan bantaran sungai sepanjang kurang lebih 50 Meter dengan jarak penanaman kurang lebih 2 Meter dan jalan persawahan sepanjang kurang lebih 150 meter dengan jarak penanaman 1 meter. Jalan tersebut rencananya akan segera dibangun sebagai jalan aspal. Sehingga besar kemungkinan tanaman tersebut sudah hidup dengan baik ataupun sudah tumbuh dengan baik pada saat melakukan pembangunan jalan aspal. Dampak yang kemungkinan terjadi adalah masyarakat akan menyadari bahwa efek penanaman yang dilakukan membuahkan hasil lingkungan yang indah dan membantu meningkatkan kualitas udara segar dan sehat pada desa Sumokali.

\section{Evaluasi Program Kerja}

Masalah kurangnya kesadaran masyarakat akan penghijauan, membuat tim Pengabdian Kepada Masyarakat dari UBHARA tergerak untuk melakukan edukasi dan sosialisasi terhadap masyarakat agar lebih perduli dengan penghijauan, melakukan penananaman 100 pohon, yang diharapkan dapat contoh agar masyarakat desa sumokali tergerak untuk meneruskan upaya penghijauan untuk meningkatkan potensi desa wisata.

Kegiatan dilakukan dengan baik berkat adanya koordinasi antara tim Pengabdian Kepada Masyarakat dengan kepala desa, dan masyarakat. Hasil evaluasi secara menyeluruh, mulai kegiatan perencanaan, sosialisasi dan pelaksanaan berjalan dengan lancar. Keberhasilan program tidak terlepas adanya keterlibatan dan partisipasi aktif mitra selama kegiatan pengabdian berlangsung, seperti dukungan kepala desa dan masyarakat desa..

\section{KESIMPULAN}

Berdasarkan uraian di atas maka dapat ditarik kesimpulan sebagai berikut:

a. Pengabdian Kepada Masyarakat dari UBHARA kelompok 078 tentang "Gerakan Penghijauan Sebagai Rintisan Desa Wisata Untuk Meningkatkan Income Masyarakat Di Desa Sumokali, Candi, Sidoarjo" berjalan dengan baik dan lancar mulai tanggal 29 Mei 2021 sampai 14 Juni 2021.

b. Kegiatan Pengabdian Kepada Masyarakat bisa dilakukan dengan baik berkat adanya koordinasi antara tim Pengabdian Kepada Masyarakat UBHARA kelompok 078 dengan kepala desa Sumokali, dan masyarakat.

c. Progam ini semakin menyadarkan pentingnya penghijauan untuk merintis Desa Wisata di Desa Sumokali, Candi, Sidoarjo. Diharapkan dengan terbentuknya Desa Wisata akan bisa meningkatkan income masyarakat. 


\section{UCAPAN TERIMAKASIH}

Program Pengadian Kepada Masyarakat dari Universitas Bhayangkara kelompok 078 di Desa Sumokali Candi Sidoarjo Jawa Timur yang dimulai sejak tanggal 29 Mei 2021 sampai dengan tanggal 14 Juni 2021 dapat berjalan dengan lancar dan dapat terselesaikan dengan baik. Ucapan terimakasih disampaikan kepada Bapak Subianto, S.P selaku Kepala Desa dan seluruh jajarannya. Terimakasih disampaikan pula untuk seluruh anggota tim Program Pengadian Kepada Masyarakat dari Universitas Bhayangkara kelompok 078, yaitu: Ahmad Fani R (1812111040); Excel Erlangga P (1813211101); Harnum Juvika S. (1813211041); Muh. Yordan Ivan I (1813211059); Irkham Istiansyah A (1812111054); Bayu Fajar Y.A.S (1812111008); Rizky Amalia (1812311002);

Pamadsen Aji (1813211063); Auliyah Janestian (1813211054); Vera Afrida L (1812111035); Akhmad Yusuf (1813211088); Eko Imroni P (1812111001); Armand Yulianto (1812311020); Melda Ashari (1812111038).

\section{DAFTAR PUSTAKA}

Adriansyah, M. A., Sofia, L., \& Rifayanti, R. (2019).Pengaruh Pelatihan Pendidikan Lingkungan Hidup terhadap Sikap Peduli Anak akan Kelestarian Lingkungan. Psikostudia : Jurnal Psikologi, 86-106, https://doi.org/10.30872/psikostudia.v5i2.2281

Arismayanti. 2015. Paradigma dan Kebijakan Pariwisata, Cakra Press, Denpasar

Hariyanto, O. I. B. (2016). Destinasi Wisata Budaya Dan Religi Di Cirebon. Ecodemica, 4(2), 214-222, https://doi.org/10.31294/jeco.v4i2.830

Hermawan, Hary. 2016. Dampak Pengembangan Desa Wisata Nglanggeran Terhadap Ekonomi Masyarakat Lokal. Jurnal Pariwisata, 3(2), 105-107, https://doi.org/10.31294/par.v3i2.1383

https://id.wikipedia.org/wiki/Sumokali\%2C_Candi\%2C_Sidoarjo

Prasetiyani, Erni. 2020. Peranan Masyarakat Mengangkat Perekonomian Kampung Kumuh Berbasis Kampung Ramah Lingkungan Sebagai Bagian Untuk Dijadikan Sebagai Desa Wisata. Destinesia: Jurnal Hospitaliti dan Pariwisata. 1(2), 89-95. $\underline{10.31334 / j \mathrm{j} . v 1 \mathrm{i} 2.844}$

Sabardila, A., Budiargo, A. D., Wiratmoko, G., Himawan, J. A., Triutami, A., Intansari, A., \& Suistri, S. (2019). Pembentukan Karakter Peduli Lingkungan melalui Kegiatan Penghijauan pada Siswa MIM Derasan Sempu, Boyolali. Buletin KKN Pendidikan, 1(2), 35-41, https://doi.org/10.23917/bkkndik.v1i2.10763 